\title{
Landsat-comparable land cover maps using ASTER and SPOT images: a case study for large-area mapping programmes
}

\author{
STEVEN E. FRANKLIN†, YUHONG HE*+, ALYSHA PAPE $\S$, XULIN GUO \\ and GREGORY J. MCDERMIDI \\ $\uparrow$ Trent University, Peterborough, ON K9J 7B8, Canada \\ $\ddagger$ Department of Geography, University of Toronto Mississauga, Mississauga, Canada \\ $\S$ Department of Geography and Planning, University of Saskatchewan, \\ Saskatoon, Canada \\ IIDepartment of Geography, University of Calgary, Calgary, Canada
}

(Received 20 May 2009; in final form 8 January 2010)

The long-term record of global Landsat data is an important resource for studying Earth's system. Given the identified gaps in Landsat data and the undetermined future status of Landsat data availability, alternatives to Landsat imagery need to be tested in an operational environment. In this study, forest land cover and crown closure maps generated from Advanced Spaceborne Thermal Emission and Reflection Radiometer (ASTER) and System Pour 1'Observation de la Terre (SPOT) data were compared to Landsat-based map products currently in use by the grizzly bear habitat-mapping program. Overall accuracies greater than $85 \%$ were obtained for both ASTER- and SPOT-based land cover maps. The ASTER and SPOT classification accuracies were higher than that achieved by Landsat. Crown closure maps derived from ASTER and SPOT data show a small increase in accuracy when compared to the Landsat products. Overall, these results demonstrate that ASTER and SPOT could provide alternative data sources for producing maps in the event of a gap in the Landsat data.

\section{Introduction}

Landsat-derived land cover and forest structure maps are a basic requirement in many regional and national scale mapping programmes (Wulder et al. 2003). The value of Landsat data lies in the length of their record and arises from their relatively high spatial resolutions. However, two gaps in Landsat data have been identified: (1) data availability and (2) data quality. Regarding data availability, the common assumption that Landsat-type sensors are operating continuously as they orbit the Earth is not in fact true (Goward et al. 2006). There are many variables that affect Landsat data availability, including system technical capabilities, mission operation decisions, and clouds (Arvidson et al. 2006). Furthermore, the two remaining Landsat observatories, Landsat 5 and Landsat 7, have exceeded their design lifetimes and will probably exhaust their fuel supply in 2010. Regarding data quality, the derivation of reliable quantitative information relies on careful processing of Landsat data, with the consideration of significant non-surface contributions such as cloud and atmospheric effects, and inter-sensor variations.

*Corresponding author. Email: yuhong.he@utoronto.ca 
To bridge the gap in the historical Landsat global coverage, a recent study provided 40 a first intensive look at the historical global Landsat data record (Goward et al. 2006). Through conduct of this analysis, Goward et al. (2006) discussed the possibility of filling the historic data gap by taking steps to embrace and document all possible collections of Landsat data, particularly from the International Cooperator holdings. In view of the undetermined future status of Landsat data availability, a Landsat 45 Data Continuity Mission (LDCM) spacecraft (LDCM-1), with its instrument payload, is currently planned for launch in December 2012 (http://landsat.usgs.gov/ about_ldcm.php). In response to the challenge of data quality, numerous preprocessing methods have been explored to remove non-surface contributions such as cloud and atmospheric effects from Landsat data and various cross-calibration analysis 50 approaches have been proposed to ensure that Landsat sets are in compatible radiometric, geometric and spectral domains. For example, the National Aeronautics and Space Administration (NASA) has sponsored the creation of an orthorectified and geodetically accurate global land data set of Landsat Multi-spectral Scanner (MSS), Thematic Mapper (TM) and Enhanced Thematic Mapper Plus (ETM+) data from 55 the past 30 years (Tucker et al. 2004).

Although significant effort is under way to fill Landsat data gaps in order to meet the needs of mapping programmes, reliance on a specific sensor may compromise an important application or perhaps jeopardize an entire mapping programme (McDermid et al. 2005). This situation suggests that alternative mapping sources should be tested even if the current Landsat data gaps are filled (Lobell and Asner 2003). A Landsat Data Gap Study team also indicated that capturing and achieving data from comparable systems could reduce the impact of a Landsat data gap (Behrens 2010).

One application that relies heavily on a stable source of medium-resolution satellite 65 imagery is the Foothills Research Institute Grizzly Bear (Ursus arctos horribilis) Research Program in Alberta (Stenhouse and Graham 2005). Satellite images, typically from Landsat sensors, are used to produce detailed land cover and forest structure maps required for modelling grizzly bear habitat and resource selection (Nielsen et al. 2004). Field data and methods used to create the Landsat-based maps 70 have been described in detail elsewhere (McDermid et al. 2005) and are summarized here:

(1) Detailed field data are collected at many tens, or even hundreds, of field locations by interdisciplinary field crews using mensuration and light interception equipment at locations stratified by ecoregion and image quality.

(2) Landsat-based land cover maps are produced using segmentation and supervised object-based classification following standard radiometric and geometric image processing.

(3) Continuous variable models of forest structure attributes (i.e. crown closure, tree species composition, and leaf area index) are produced using regression 80 techniques.

Accuracies for the Landsat-based classifications have been typically reported to exceed $80 \%$ overall using these methods, and the regression models for vegetation properties (e.g. crown closure) are reliable when appropriate field data are available to calibrate the relationships between reflectance and forest structure.

Landsat data have suffered from availability and quality issues, and operating Landsat sensors are currently threatened or are technically failing to deliver 
high-quality data; in addition, an LDCM is at least three years away (Wulder et al. 2008). This situation suggests that alternate medium spatial resolution imagery should be tested for suitability in wildlife habitat mapping work. As the Advanced Spaceborne Thermal Emission and Reflection Radiometer (ASTER) and System Pour 1'Observation de la Terre (SPOT) sensors have the potential ability to meet the large-area coverage needs of land cover studies, imagery from these two sensors may provide alternative data sources for use in the mapping programme. Specifically, ASTER data with a swath width of $60 \mathrm{~km}$ collects multi-spectral data with spectral 95 resolutions of $15-30 \mathrm{~m}$. The ASTER acquisition time is very similar to Landsat, which results in consistent illumination and spectral comparability between ASTER and Landsat (Wulder et al. 2008). SPOT 4 and SPOT 5 acquire Earth-observation data with a swath width of $60 \mathrm{~km}$, and both satellites carry sensors that acquire imagery in the visible, near-infrared and shortwave infrared regions with 10-20 m spatial 100 resolution.

ASTER and SPOT imagery has been used frequently in vegetation and land cover mapping applications (Kato et al. 2001, Lewinsky 2005). For example, one recent study explored the potential and effectiveness of ASTER data for mapping forest vegetation composition and structure to aid fire propagation simulation models and fire risk assessment (Keramitsogloua et al. 2008). Similar examples using SPOT data for land cover studies are even more common, largely as a result of the longer-term SPOT historical data (Wulder et al. 2008). A few examples of mapping work using SPOT multi-spectral data include detecting forest defoliation (Muchoney and Haack 1994), identifying damage caused by inundation of forest ecosystems (Michener and Houhoulis 1997), and mapping forest harvesting patterns (Desclée et al. 2006). In New Zealand, SPOT multi-spectral data have been acquired to develop a land cover database (Ministry for the Environment 2005), and Canada has purchased a complete national coverage of SPOT 4 data to be collected over the period 2005 to 2010.

In this paper, we evaluate the utility of ASTER and SPOT images for delivering land cover and vegetation structure products that are comparable to the Landsat Thematic Mapper (TM)-based products currently in use by the Grizzly Bear Research Program. The first task is to determine the accuracy with which land cover classification maps and crown closure models, based on ASTER and SPOT 5, can be produced, using the same coverage area, training sets and classification method as in the current Landsat-based programme. The second task is to determine the spatial differences that might exist in the mapping products. One way to examine such differences is to compare landscape metrics, which are used in habitat mapping to relate to wildlife resource selection and habitat structure. Several previous studies have conducted intersensor map accuracy comparisons for habitat mapping (e.g. Capolsini et al. 2003, Joshi et al. 2008). In general, these studies covered a broad range of satellite sensors and compared the different aspects of the sensors for particular land cover classes or feature detection. The present study focused on the accuracy and the spatial quality; in other words, the ability to provide alternatives to Landsat TM imagery for land cover and forest structure mapping in a large-area habitat application.

\section{Data and methods}

\subsection{Study area}

The Foothills Research Institute Grizzly Bear Research Program aims to map all grizzly bear habitat in Alberta, Canada (figure 1). An area of approximately $385 \mathrm{~km}^{2}$ 


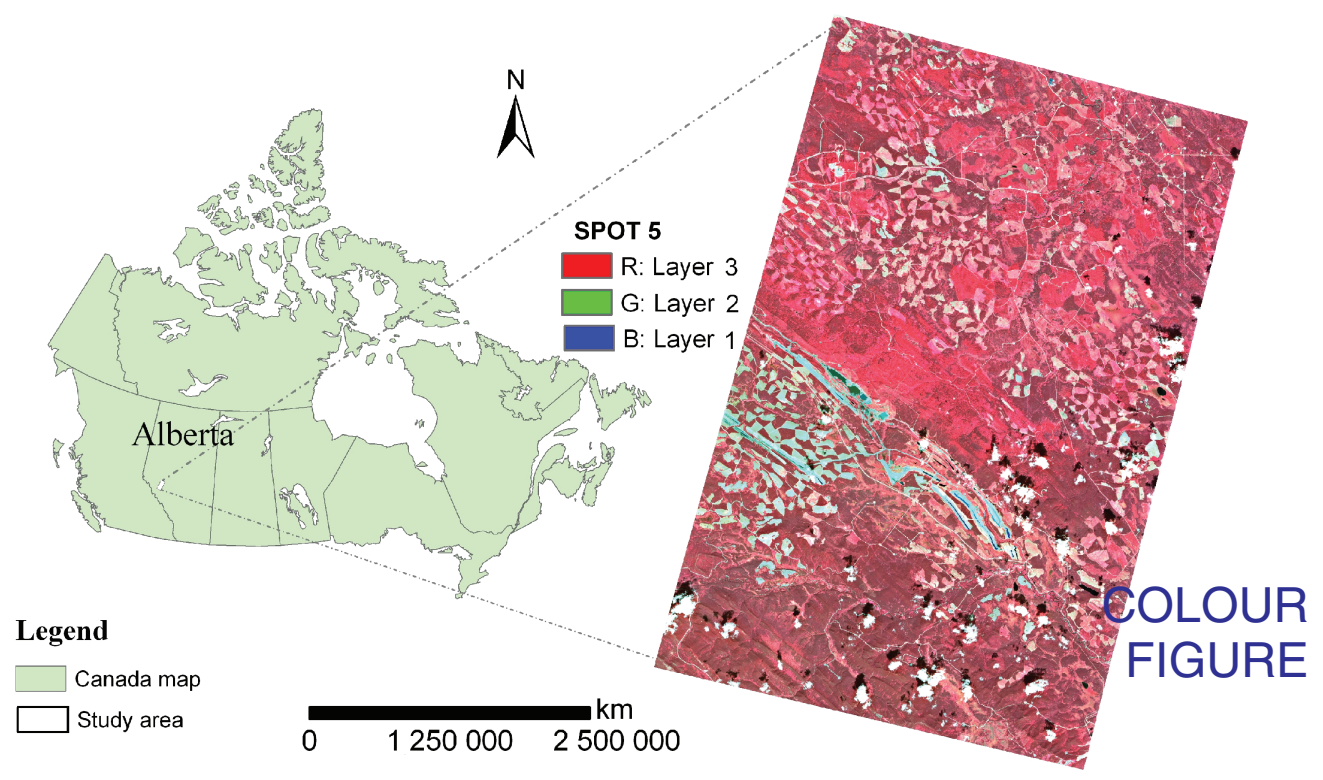

Figure 1. Location of the study area in Alberta and a SPOT image.

contained within Landsat Path/Row 44/23 and located on the eastern slopes of the Rocky Mountains was selected for the mapping comparison. The area represents prime grizzly bear habitat but is also an area of significant human use and land use change due to forestry practices (e.g. harvesting, plantations) and oil and gas exploration and development. This boreal forest environment contains pure and mixed forest stands of white spruce (Picea glauca), lodgepole pine (Pinus contorta), and trembling 140 aspen (Populus tremuloides), along with considerable areas of herbaceous meadows, woody shrubs, and treed and non-treed wetlands.

\subsection{Field data collection}

Several field campaigns have been conducted in support of the remote sensing activities in the Foothills Model Forest Grizzly Bear Research Program from 2000 to 2005, and this research used field data from each campaign. To ensure complete representation and reduce sampling error (Husch et al. 2003), the fieldwork took place across a stratified random sample generated on the basis of some initial classification work performed by the consulting group GeoAnalytic (GeoAnalytic, 1999). To accommodate positional errors, sampling was limited to homogeneous stands at least 1 ha in size, concentrated in areas between 60 and $300 \mathrm{~m}$ of known access features. The selection of homogeneous stands was accomplished through field checks and the use of Alberta Vegetation Inventory (AVI) data, which was produced by provincial and private photointerpretation experts who map homogeneous polygons on the basis of tone, texture, pattern, size, shape, shadow, and association (McDermid et al. 2005). In an attempt to ensure the acquisition of a sample that represented the range of forest structural conditions occurring across the study area, the pattern of tasseled cap wetness values (Kauth and Thomas 1976) extracted from Landsat TM imagery of the sample sites was matched to the distribution of wetness values 
observed across the entire study area, under the assumption that wetness had a 160 positive relationship with the structural complexity of the forest canopy and the optical depth of water in leaves (Cohen et al. 1995), and thereby provided an effective gradient across which to sample. Plots were $30 \mathrm{~m} \times 30 \mathrm{~m}$, which is approximately the same as one Landsat TM pixel.

Land cover and crown closure were collected for each field plot, but crown closure 165 data were only measured for some random sites, which were selected from the field sampling layer using Hawth's Analysis Tools for ArcGIS. Land cover is a description of the predominant vegetation type in the plot and defines the categorical classes in the land cover map legend. Land cover was obtained from an ocular estimate by trained field personnel. The land cover classes are as follows: Upland Tree, Wetland Tree, Upland Herb, Wetland Herb, Shrub, Water, Barren Land, and Snow/Ice.

Crown closure is the percentage of ground covered by a vertical projection of the outermost perimeter of the crowns in a stand. It was measured using digital hemispherical photography and was processed in the laboratory using WinSCANOPY 2003 (Regent Instruments, Ste-Foy, Quebec, Canada). WinSCANOPY works by 175 calculating a canopy (also twig, branch, and stem) to sky ratio called the gap fraction, from which crown closure can be derived.

As both field data and images were acquired from different years, visual prechecking was carried out to select the sampling sites shown to be stable and undisturbed. After removing the sites with distinct change (such as some treed plots that had been harvested), a total of 240 land cover points were kept within the imagery-overlapped area to aid in land cover classification and a total of 52 crown closure points were kept for the imagery-overlapped area. Two-thirds of the selected land cover points were used as training points to run the classification and the remaining points were used to evaluate the classification map accuracy. Considering that crown closure models would be more robust using a large sampling size, crown closure data within each satellite scene were used to build the crown closure model. Thirty independent crown closure points randomly selected from the imagery-overlapped area using Hawth's Analysis Tools were held to assess the crown closure map accuracy.

\subsection{Remote sensing data acquisition and preprocessing}

In this study, analysis was conducted based on two sets of images. The first set included three images from ASTER, SPOT 5, and Landsat sensors separately, acquired at different times over the growing season and in different years (table 1). The ASTER image with three visible and near-infrared (VNIR) bands and six shortwave infrared (SWIR) bands was acquired on 17 September 2007, covering approximately $60 \mathrm{~km}$ by $60 \mathrm{~km}$. The SPOT 5 multi-spectral image was acquired on 21 July 2005. The SPOT scene covered approximately $60 \mathrm{~km}$ by $60 \mathrm{~km}$, and includes three VNIR bands and one SWIR band. The existing classification and forest structure maps for the selected area were derived from a Landsat TM image from 15 September 2005. Images with such differences may influence the ability of the imagery to perform in the required mapping tasks, as is the case in the existing Landsat-based mapping large-area map, which was constructed with multiple Landsat scenes acquired over several years (McDermid et al. 2005).

To further confirm the results delivered from the first set of images, a second set including a SPOT image and a Landsat image was acquired from the same week for 
S. E. Franklin et al.

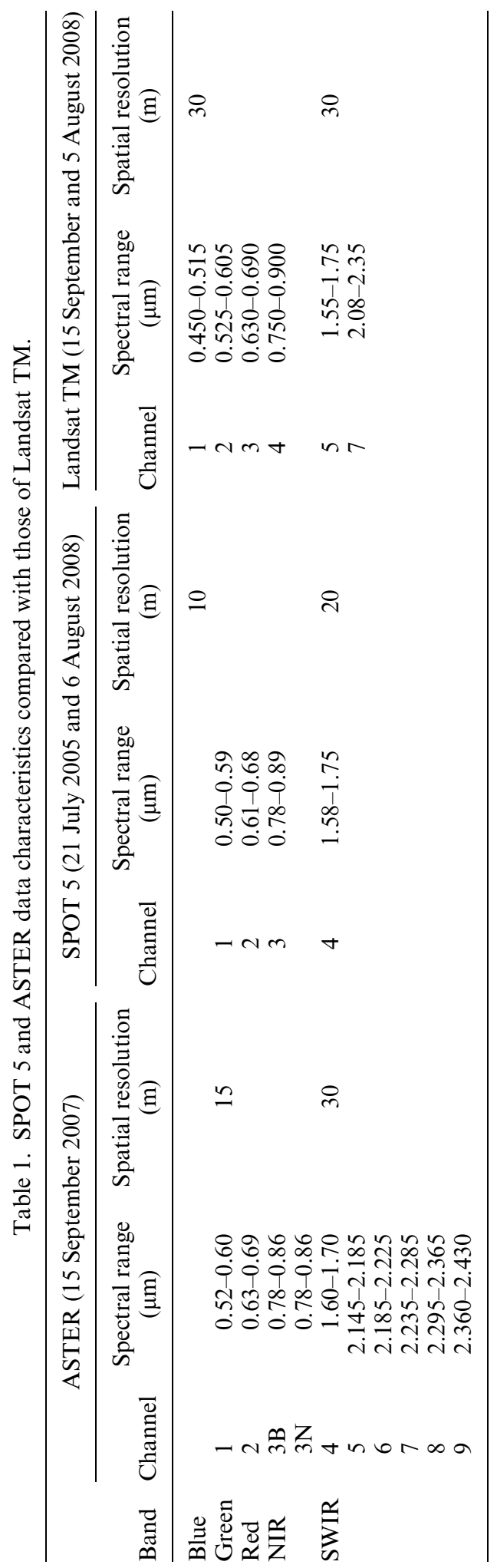


analysis. This second set includes a SPOT 5 image acquired on 6 August 2008 and a Landsat TM image obtained on 5 August 2008.

For comparison purposes, the ASTER and SPOT 5 images were orthorectified following the procedure that was used previously to produce Landsat map products (McDermid et al. 2005). Specifically, orthorectification was performed using the satellite orbital math-model approach with an available digital elevation model (DEM; PCI Geomatica OrthoEngine 10.X; see Toutin 1995). The DEM was created through interpolating of the National Topographic Database 1:50 000 digital map contours, contours, spot heights, and water body polygons. A smoothing algorithm (Hutchinson 1989) was used to eliminate stepping and pit artefacts commonly associated with similar medium-quality elevation models. The DEM was created at $30 \mathrm{~m}$ resolution, and distributed by 1:250 000 map sheet. A root mean square error (RMSE) $<0.5$ pixel was estimated based on 25 ground control points. After correction, the ASTER and SPOT5 images were resampled using a nearest-neighbour algorithm to produce a $15-\mathrm{m}$ and a $10-\mathrm{m}$ grid, respectively. Atmospheric correction was then performed using the ATCOR-2 program in PCI Geomatica (Richter 1990) to retrieve the surface reflectance by removing the atmospheric effects. Atmospheric corrections are mandatory in this study because multi-temporal image data are used for the estimation of biophysical parameters (Song et al. 2001). All calibration coefficients were obtained from the image header files for SPOT and ASTER imagery and from the website (http://landsat.usgs.gov/science_L5_cpf.php) for Landsat imagery in which the latest calibration coefficients were provided. Finally, the corrected images were clipped to the overlapped study area, approximating $1126 \mathrm{~km}^{2}(26.5 \mathrm{~km} \times$ $42.5 \mathrm{~km}$ ), as shown in figure 1 .

\subsection{Object-based image segmentation}

Existing Landsat-based map products were cropped to cover spatially identical areas to the SPOT and ASTER imagery. To create Landsat-comparable land cover maps using the ASTER and SPOT images, a multi-resolution image segmentation was performed using the software Definiens Professional 5.0. This process uses an iterative, bottom-up, region-merging technique starting with individual pixels. Small 235 objects are merged into larger ones, and the size of the object is controlled by a threshold defined by the scale, shape, and compactness parameters specified by the user in a local optimization procedure that minimizes the weighted heterogeneity of each resulting image object (Darwish et al. 2003). The scale, shape, and compactness parameters for existing Landsat products were set to 10,0.2, and 0.2, respectively. The basic principle for defining the appropriate thresholds for ASTER and SPOT imagery was that the segmented objects from ASTER and SPOT should be similar in size and shape to that in the Landsat image.

A large variety of quantitative segmentation evaluation approaches are proposed in the literature. In this study, three commonly used methods were applied to determine the best segmentation results: (1) geometric attributes such as mean shape index (MSI), mean patch size (MPS), and number of patches (NUMP) (Meinel and Neubert 2004), (2) a visual score to rate the quality of segmentation (0 poor, 1 medium, 2 good) (Neubert and Meinel 2003), and (3) the distance to a perfect match $(D)$ calculated from over- and undersegmentation (Clinton et al. 2008). The parameter 250 combinations were examined for the scale, shape and compactness according to $\{10$, $15,20,25,30,35,40,45,50,55,60\} \times\{0.1,0.3,0.5,0.7,0.9\} \times\{0.1,0.3,0.5,0.7,0.9\}$, 
respectively. These measures were computed using the resultant segmentation layer from each parameter combination. For training sets, a total of 54 objects were selected randomly including all types of land cover classes.

Table 2 shows the suitable combinations in terms of segmentation accuracy assessment. The most suitable parameter combination to segment SPOT imagery is scale = 55 , shape $=0.2$, and compactness $=0.2$, as this combination provided the objects with geometric attributes similar to Landsat products, a higher visual score, and a lower $D$ value. The most suitable parameter combination to segment ASTER imagery is scale 260 $=20$, shape $=0.2$, and compactness $=0.2$.

\subsection{Land cover classification and crown closure modelling}

The resulting image objects from the segmentation step were then subjected to supervised, nearest-neighbour, object-oriented classification based on the available channels, considering both the spectral and spatial properties of those objects. In 265 total, 160 training areas were selected to drive the classifier for this area (McDermid et al. 2005). Accuracy assessment was conducted at 80 independent field sites that were not used in the classification. Classification accuracies were summarized using errors of commission and omission and the Kappa coefficient of agreement.

Linear regression models were created to estimate crown closure based on 270 ground measurements and the Normalized Difference Vegetation Index (NDVI). As we found that there were significant differences among the five images when performing the intersensor comparison, we developed a crown closure model for each image. The remote sensing data were extracted and processed from each field site. Each of the selected models was evaluated by the coefficient of 275 determination. A more powerful performance measure involved comparing the results of the models with an independent ground data set. The RMSE and map accuracy (MA; Pu and Gong 2004) were also calculated using 30 independent field samples, and the formulae:

$$
\mathrm{RMSE}=\sqrt{\frac{1}{n} \sum_{i=1}^{n}\left(x_{i}-\hat{x}_{i}\right)^{2}}
$$

Table 2. The selected segmentation accuracy assessment results for selected area with ideal parameter combinations.

\begin{tabular}{lcccccccccc}
\hline $\begin{array}{l}\text { Segmentation assessment } \\
\text { measures }\end{array}$ & $\begin{array}{c}\text { Landsat } \\
\text { products }\end{array}$ & \multicolumn{3}{c}{ SPOT } & \multicolumn{5}{c}{ ASTER } \\
\hline Scale parameter & 10 & 50 & 55 & 60 & 15 & 20 & 25 \\
Shape & 0.2 & 0.2 & 0.2 & 0.2 & 0.2 & 0.2 & 0.2 \\
Compactness & 0.2 & 0.2 & 0.2 & 0.2 & 0.2 & 0.2 & 0.2 \\
Mean shape index (MSI) & 1.73 & 2.36 & 2.35 & 2.40 & 1.78 & 1.83 & 1.87 \\
Mean patch size (MPS), ha & 17.02 & 12.62 & 14.61 & 17.98 & 11.12 & 16.97 & 24.59 \\
Number of patches (NUMP) & 55 & 74 & 64 & 52 & 84 & 56 & 36 \\
Visual score & & 1 & 2 & 1 & 1 & 2 & 1 \\
Oversegmentation & & 0.30 & 0.29 & 0.21 & 0.46 & 0.33 & 0.26 \\
Undersegmentation & & 0.33 & 0.31 & 0.39 & 0.16 & 0.29 & 0.39 \\
Distance to a perfect match $(D)$ & & 0.48 & 0.46 & 0.47 & 0.51 & 0.46 & 0.51 \\
\hline
\end{tabular}




$$
\mathrm{MA}=\left(1-\frac{(\mathrm{RMSE})}{\frac{1}{n} \sum_{i=1}^{n} X_{i}}\right) \times 100.00 \%
$$

where $n$ is the number of sites, $i$ is each site sequence, $x_{i}$ is the measured value at site $i 280$ Q1 Q2 and $\hat{x}_{i}$ is the simulated value calculated from the regression model at site $i$.

Final comparisons involved visual analysis of the map output and the calculation of landscape metrics to compare spatial structure. Three landscape metrics [percentage cover (PC), MPS, and edge density (ED)] were selected to further determine the spatial accuracy of the classification maps because these metrics have been shown in 285 the grizzly bear resource selection analysis to be ecologically meaningful predictors of grizzly bear habitat use (Linke et al. 2005). The PC is defined as the percentage of the landscape covered by each land cover class. The accuracy of classification maps was evaluated based on comparisons of the areal extent of the classes among the derived maps. This approach is non-site-specific, but its limitation is that a map could easily display the classes in the correct proportions but in the incorrect locations (Foody 2002). The MPS is the average size of patches for each land cover class. ED is the length of land cover edge divided by the landscape area. The MPS and ED give the initial assessment of spatial heterogeneity and scale of analysis. Similar landscape metrics among the classification results ensure more reliable or comparable classifica- 295 tion maps (Antrop and Van Eetvelde 2000).

\section{Results}

\subsection{Comparison of classification results}

The results of the Landsat-based classification and the new ASTER-based and SPOTbased classification are displayed in table 3 and figure 2. Detailed comparisons of the 300 classification maps are presented in figure 3. Classification accuracies were $83.8 \%$ for the 2005 Landsat and $83.1 \%$ for the 2008 Landsat, slightly higher at $87.5 \%$ for the 2005 ASTER, and much higher at $92.5 \%$ for the 2005 SPOT and $96.4 \%$ for the 2008 SPOT. Kappa coefficients were 0.718 and 0.723 for the 2005 and 2008 Landsat classifications, respectively, 0.779 for the ASTER, and 0.874 and 0.941 for the SPOT classifications. The Landsat-based land cover classification accuracy was comparable to that reported by McDermid et al. (2005) in a larger accuracy assessment evaluation covering the entire grizzly bear habitat mapping program.

The higher spatial resolution of the ASTER and SPOT images appeared to provide greater detail in some of the class features visible in figure 2. For example, some of the smaller herb features were more finely mapped in those classifications. A noteworthy pattern of differences in accuracy between the Landsat-based classifications and the ASTER-based and SPOT-based classifications occurred in the upland herb classes. The upland herb class was more accurately mapped using the ASTER (user's accuracy of $92.9 \%$ ) and SPOT data (user's accuracy of $92.9 \%$ for 2005 SPOT and $85.7 \%$ for 315 2008 SPOT) than using the Landsat data (user's accuracy of $57.1 \%$ for 2005 Landsat and $35.7 \%$ for 2008 Landsat). Classification accuracy for the shrub land cover class did not show a consistent difference when using ASTER or SPOT data. Among the three classifications, the accuracy of the upland tree (the dominant forest class) was the same for all three: user's accuracy $>95 \%$ in Landsat, ASTER, and SPOT. 
S. E. Franklin et al.

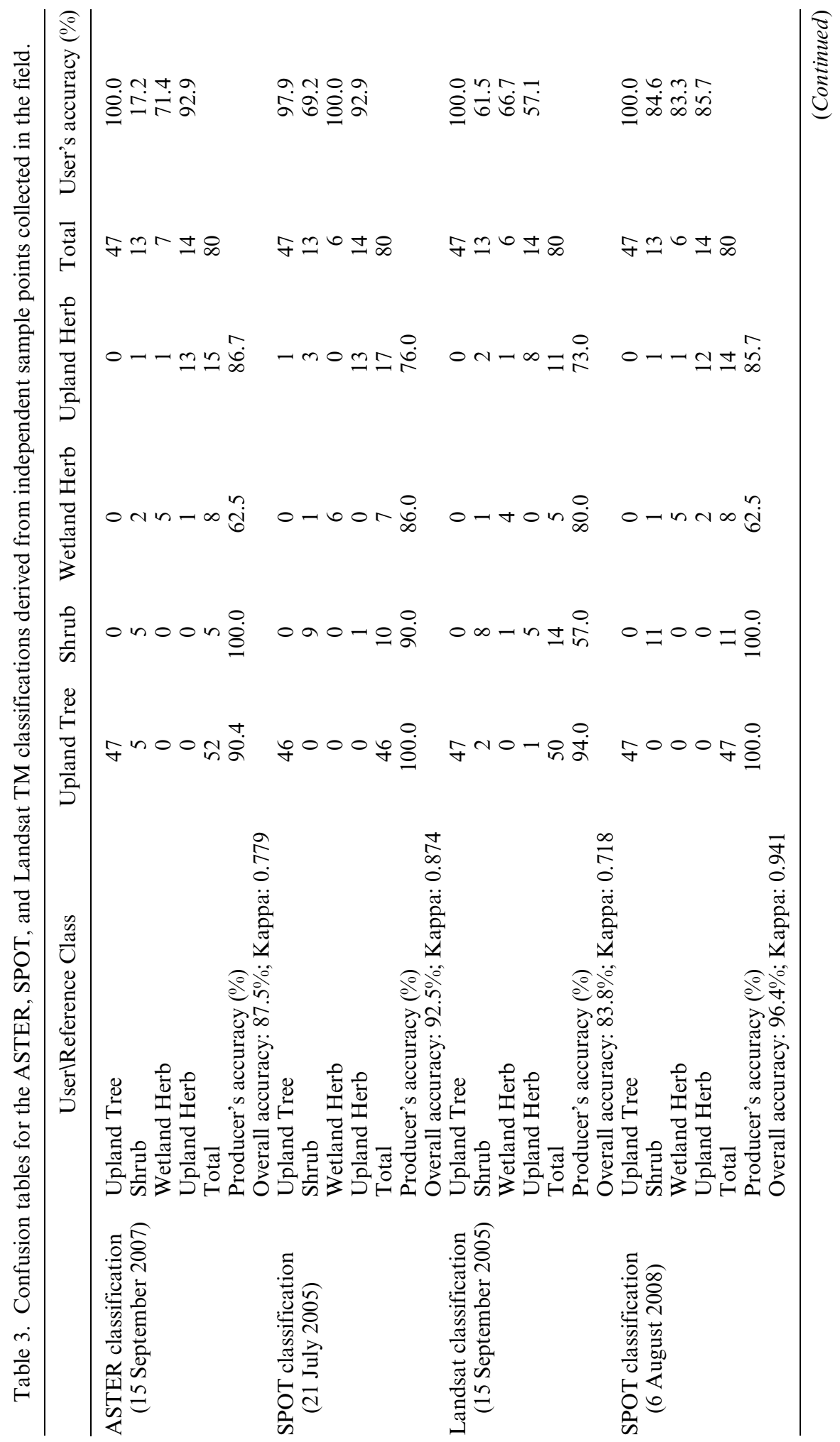


Alternatives to Landsat imagery

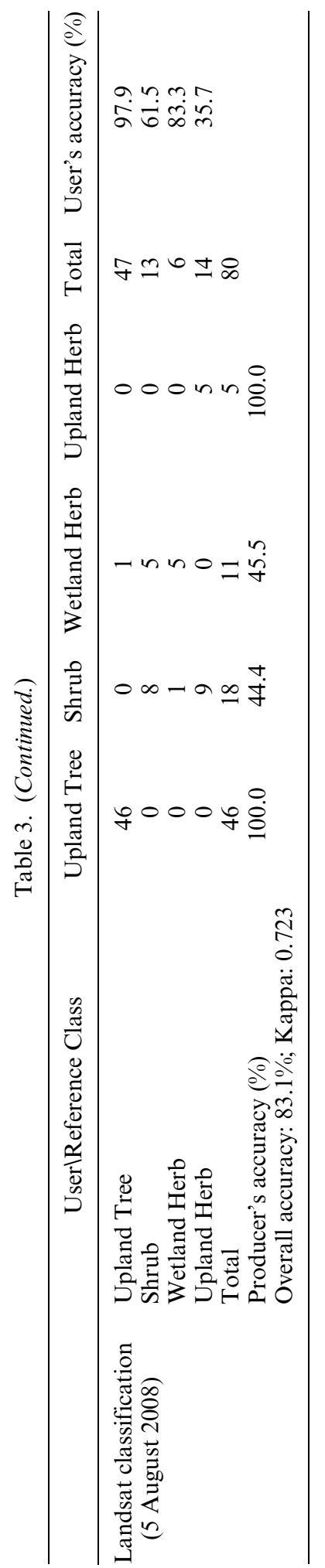




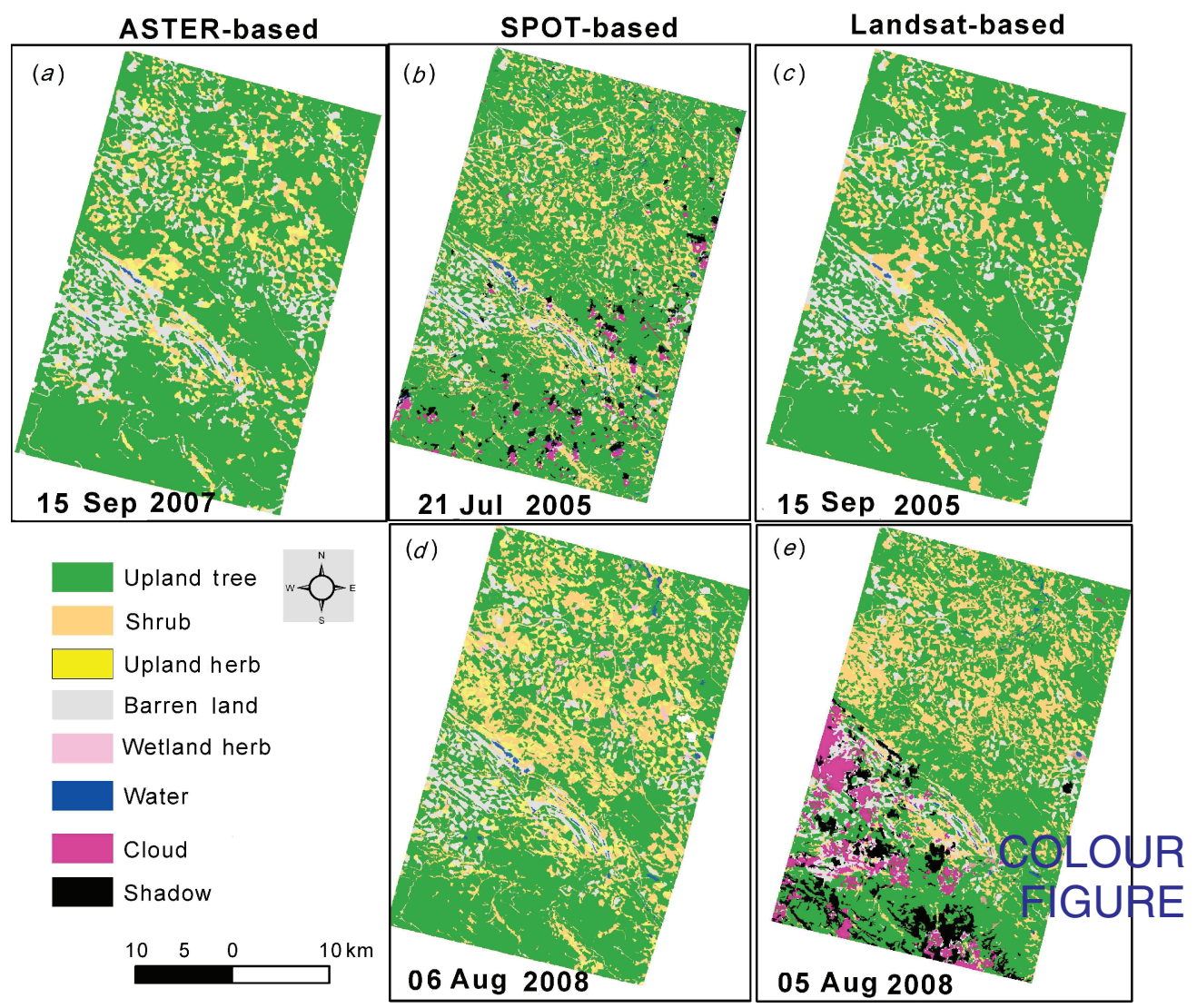

Figure 2. The classification maps produced using ASTER, SPOT and Landsat data.

To determine whether the vegetation patches in the ASTER-and SPOT-based maps were comparable to Landsat-based maps, we visually identified differentiation and similarity in the classification maps (figure 3). In the area with major change (figure 3(a)), the images acquired from 2007 and 2008 appeared to accurately capture the new disturbance in the left bottom corner. In comparison with ASTER, the higher 325 spatial resolution SPOT data provided an even better classification map. The middle map in figure 3(a) showed the identification of access roads and small well sites that had been accurately mapped using the SPOT data acquired in 2005 and 2008. These small features were often relatively poorly mapped using Landsat imagery because of the relatively coarse spatial resolution (Pape and Franklin 2008), and this preliminary 330 example suggests that the potential exists to identify these features using SPOT imagery. In the area with minor change (figure $3(b)$ ), the objects, such as cutblocks, are identical in the classification maps; however, ASTER and SPOT classification maps showed more of the herb class around the edges of the cutblocks or roads. This is an example where the ASTER and SPOT classifications may have classified land 335 cover more accurately despite some errors of omission within the herb class.

Landscape metrics were calculated and are summarized in table 4 to further compare the spatial accuracy of the classification maps. The PC showed that the 
(a)
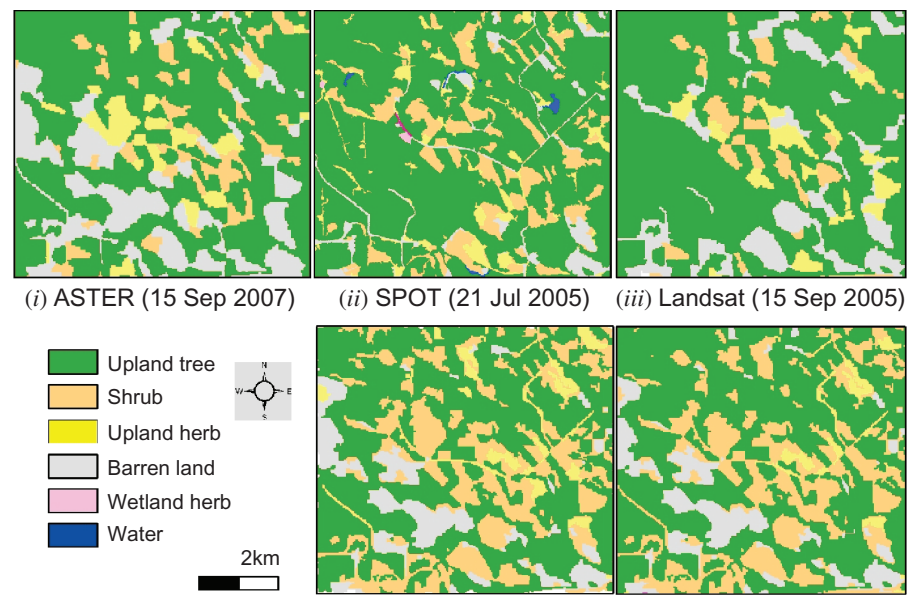

(iv) SPOT ( 06 Aug 2008) (v) Landsat (05 Aug 2008)

(b)

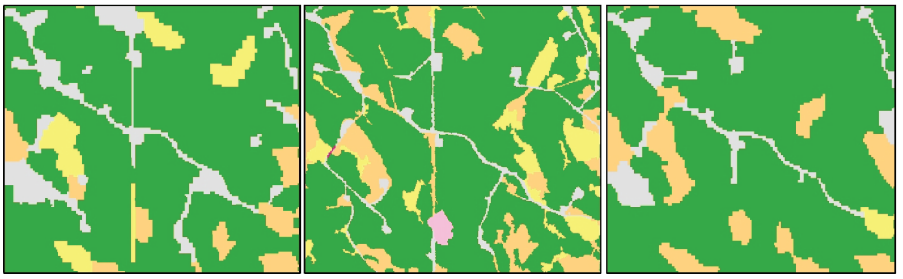

(i) ASTER (15 Sep 2007)

(ii) SPOT (21 Jul 2005)

(iii) Landsat (15 Sep 2005)
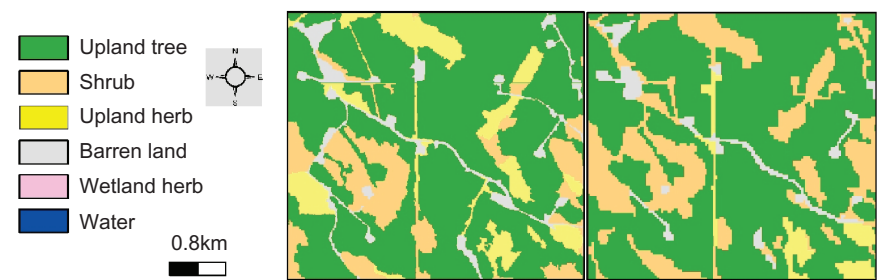

COLOUR FIGURE

(iv) SPOT (06 Aug 2008) (v) Landsat (05 Aug 2008)

Figure 3. Comparison of classification maps in two areas produced using ASTER, SPOT and Landsat data: (a) area with major change; $(b)$ area with minor change.

upland tree class always dominated the study area, followed by shrub, barren land, and herb. Considerable differences between the classification maps were evident, in that 340 SPOT and ASTER had less upland trees but more shrubs and herbs. In comparison with the PC in the 2005 classification maps, shrub in both 2008 Landsat and SPOT classification maps increased dramatically but barren land decreased. A possible explanation is that some former barren land (e.g. cutblocks) is now occupied by shrub.

In correspondence with the largest PC, the upland tree class had the largest MPS and ED in comparison with other classes. The differences in the three sensor-based classifications were obvious for the upland tree class as well. The SPOT-based classification had the smallest MPS but the largest ED for the upland tree class when compared with those in the ASTER- and Landsat-based classification maps. This result is not surprising as the segmented objects from SPOT imagery were smaller 350 
S. E. Franklin et al.

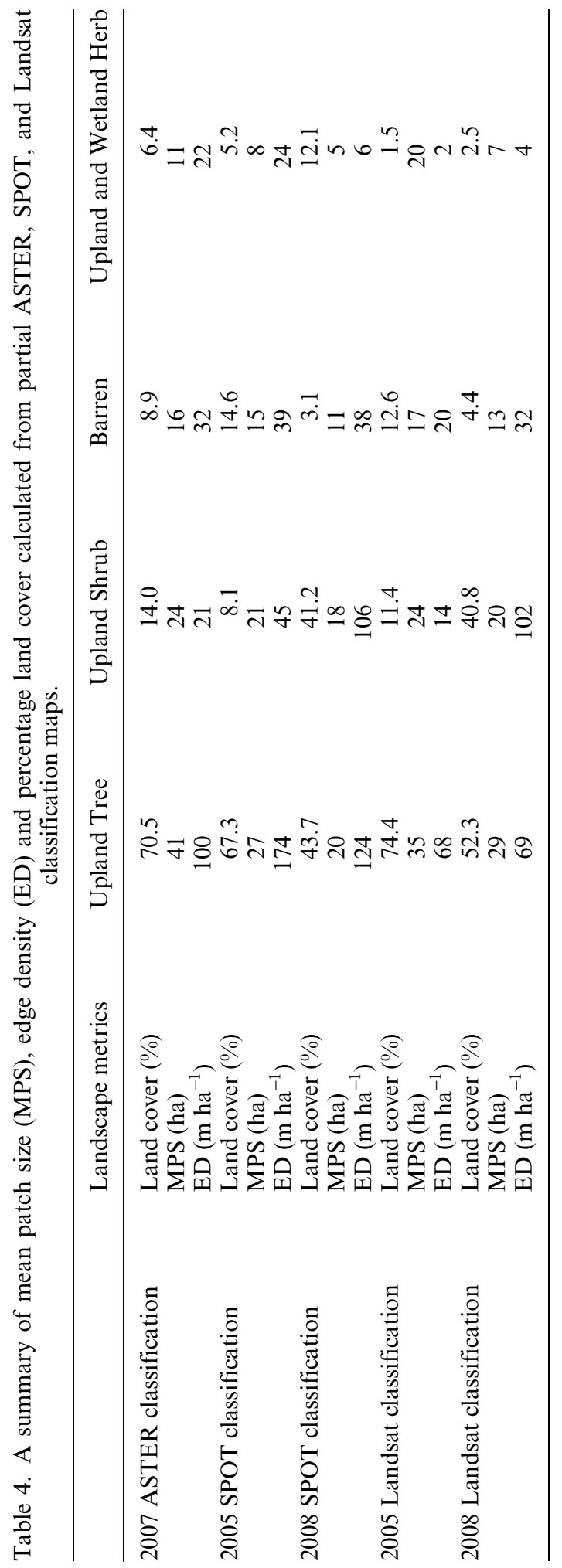



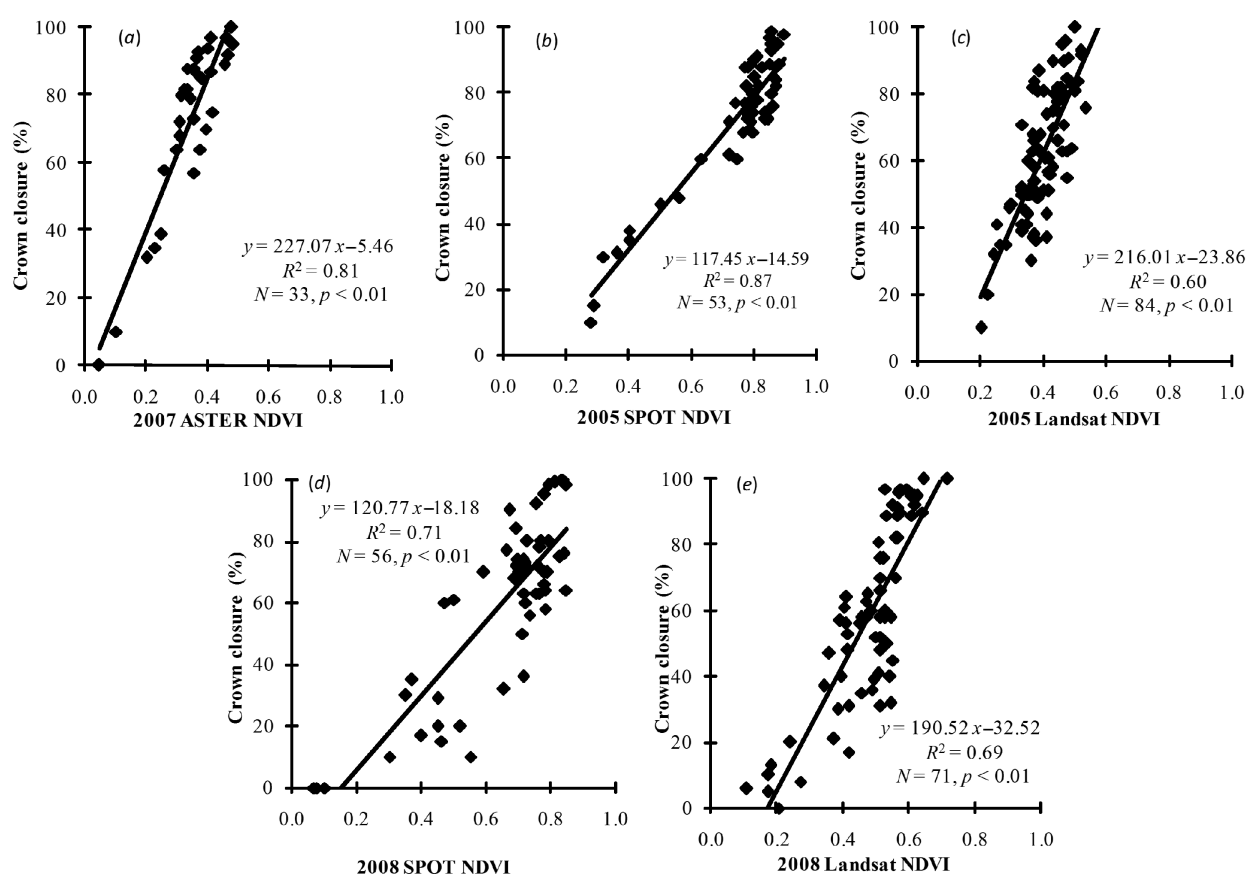

Figure 4. Regressions of crown closure and NDVI derived from five images. $N$ is the number of observations.

in comparison with those from the ASTER and Landsat images (table 2), although significant attempts were made to find appropriate classification thresholds. The barren class was relatively uniform and had clear boundaries within the study area, resulting in a similar MPS and ED among the five classification maps. Shrub and herb classes showed different MPS and ED among classification maps. This is also 355 expected considering that shrub and herb had small patches, blurry boundaries, and their sizes varied temporally.

\subsection{Crown closure models and maps}

The crown closure models for five images all were developed with the NDVI as the independent variable (figure 4). The coefficients of determination $\left(R^{2}\right)$ for five models 360 were relatively high, at 0.81 for ASTER, 0.87 for 2005 SPOT, 0.71 for 2008 SPOT, 0.60 for 2005 Landsat, and 0.69 for 2008 Landsat (figure 4). Although the $R^{2}$ for the Landsat model was lower than that for the ASTER and SPOT models, the sampling size for the Landsat scenes was considerably greater. Given the variety of vegetation classes over the study area, the $R^{2}$ for these models are acceptable for most applica- 365 tions, including the habitat mapping analysis (McDermid et al. 2005).

Crown closure maps were calibrated using ground truth data. The results indicate a fairly strong estimated strength for crown closure mapping. The crown closure model for 2005 SPOT was a particularly effective model (figure 5, RMSE $=8.8, \mathrm{MA}=$ $89.6 \%$ ). The crown closure model for 2007 ASTER ( $\mathrm{RMSE}=13.6, \mathrm{MA}=84.0 \%$ ) was 370 a somewhat less powerful estimator. The crown closure model for 2008 SPOT (RMSE $=14.6, \mathrm{MA}=82.8 \%$ ) showed the least power for crown closure estimation in 


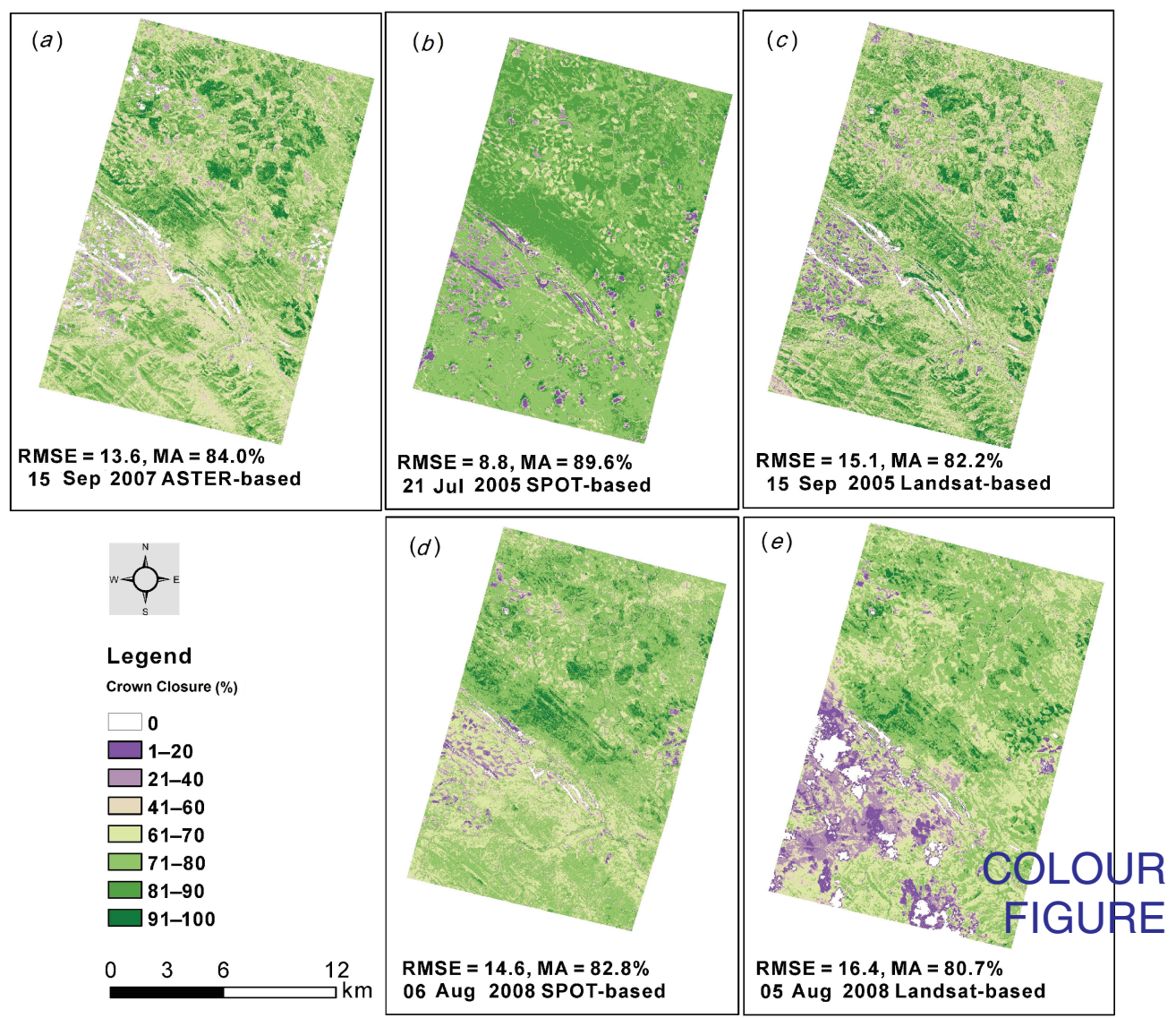

Figure 5. Crown closure maps produced from ASTER, SPOT and Landsat data.

comparison with 2005 SPOT and 2007 ASTER. One possible explanation for this discrepancy is the time difference between the field data collection and imagery acquisition. However, our results indicate a much higher accuracy for SPOT and 375 ASTER datasets than those obtained using the Landsat TM dataset (RMSE $=15.1$ and $\mathrm{MA}=82.2 \%$ for 2005 Landsat, and $\mathrm{RMSE}=16.4$, MA $=80.7 \%$ for 2008 Landsat).

The accuracy of the crown closure maps derived from the three images were also interpreted visually. Although the crown closure values for the same location varied in 380 the different maps and the 2008 Landsat-based crown closure map had relatively lower crown closure values at the bottom left corner (resulting from clouds and shadow) (figure 5), the crown closure maps generally provided common spatial patterns of vegetation across the study area. Noteworthy patterns included: (1) the difference in crown closure distributions between the northern and the southern study 385 area, with higher crown closure in the northern portion and lower crown closure in the southern portion; (2) open and semi-open areas that were distributed as concentrated in the centre west area; and (3) recently clearcut lands in the northwest corner. The specific interpretation for each map also showed consistent results with the accuracy 
assessment (figure 5). For example, SPOT was fairly well balanced although an 390 overestimation at the low end of the crown closure gradient was noted. The ASTER-based crown closure map showed a tendency to underestimate the proportion of crown closure in the forest closed condition. The Landsat-based map had a strong tendency towards underestimation at the low crown closure, as witnessed by the closed condition being misclassified as semi-closed and the semi-close category 395 misclassified as open.

\section{Discussion and conclusions}

Given the identified gaps in historical Landsat data and the undetermined future status of Landsat data availability, a thorough knowledge of the possibilities of replacing Landsat data with other information is needed in many mapping programmes at regional or even national scale. This situation applies to map construction and map update applications, such as those required in the grizzly bear habitat application (McDermid et al. 2005). In this paper, we observed that ASTER and SPOT imagery performed at least as well as, and often better than, Landsat sensor data in classification and crown closure modelling in mapping grizzly bear habitat in 405 Alberta's Rocky Mountains. These results suggest that the ASTER and SPOT satellite sensors do provide alternatives to Landsat imagery in a medium-scale land cover and forest structure mapping application and are a possible update information source.

The technical specifications of the sensors must be considered when evaluating their 410 suitability for mapping forest structure and land cover. In general, the higher spatial resolution of the ASTER and SPOT imagery appeared to enable smaller disturbance features (e.g. well-sites and access roads) to be identified more reliably than could be accomplished using Landsat sensor data. However, certain disadvantages are apparent when using ASTER and SPOT imagery for large area mapping. For example, the size of the standard scene for both ASTER and SPOT data is $60 \mathrm{~km}$ by $60 \mathrm{~km}$, and approximately nine ASTER or SPOT scenes are needed to cover the area of one Landsat image. Consequently, the mapping effort can be expected to be considerably more demanding (e.g. removal of seamlines). In large-area applications, such as mapping all of Alberta's grizzly bear habitat (McDermid et al. 2005), such image 420 sources are not advantageous compared to Landsat imagery. The increased cost, computational time and processing efforts due to increased spatial resolution and inherent noise alone may prevent effective large-area mapping. In general, a full SPOT colour or black-and-white scene $(60 \mathrm{~km}$ by $60 \mathrm{~km})$ can range from $€ 1900$ (about US\$2518) to $€ 8100$ (about US\$10 734.98) (SPOT Image, 2008). In addition, 425 SPOT data are typically purchased with a standard licence for one user, or a multilicence agreement for multiple users, and the data cannot be redistributed. While ASTER data are inexpensive (US\$80 per archived scene), if ASTER images are unavailable, a programming request is also needed. However, it should also be kept in mind that the issue of price and licences is difficult to apply universally, as any large 430 data user would be able to negotiate alternative price structures and licences.

Although the same methods were used with all the images to derive the mapping products, the different image acquisition dates, spatial resolutions and spectral regions will influence the comparisons. Regarding different image acquisition dates, a per-scene-based classification and modelling was performed. The overall accuracy 435 assessment may still be affected by image seasonality, which is a stronger influence in 
certain land cover classes. For example, the increased herb class around the edges of cutblocks could be observed in the 2005 SPOT-based classification maps compared to that class mapped in 2005 Landsat and 2007 ASTER classification products (figure $3(b)$ ). This might result from the superior ability of the SPOT image in the identification of smaller objects, with different spectral resolutions, but might also be partially associated with vegetation seasonality; the 2005 SPOT image was acquired in late July, the peak growing season, while 2007 ASTER and 2005 Landsat images were obtained in mid-September, much later in the growing season. For confirmation, a parallel comparison of SPOT and Landsat images acquired during the same time period (early August of 2008) was conducted. It was found that the SPOT classification accuracy was consistently $10 \%$ higher than Landsat-based maps in terms of overall accuracy.

Classifying land cover classes using more than one type of sensor data with an object-based approach does introduce more complexity in determining the classification threshold (i.e. the scale, weight, and shape parameters). Using multi-resolution data, reconciling object-based classification parameters is crucial for many remote sensing applications (Capolsini et al. 2003). Although it is possible to build more detailed and accurate classification maps based on finer ASTER and SPOT images, the drawback is that classifications might result in several different land cover objects within a single object in Landsat-based classification map. The comparison within multi-sensors may then be much more difficult. In this analysis, because we wanted to compare ASTER and SPOT classifications to Landsat, the algorithm was forced to operate with a relatively larger classification threshold to obtain similar-sized objects. Our analysis of segmentation assessment suggests that this task was only partially 460 successful.

According to landscape metrics analysis, it was found that a nearly fourfold increase in herb cover from Landsat to SPOT could be observed from both 2005 and 2008 images. Such a difference is probably due to the fact that SPOT images with high resolution could identify small vegetation patches, which are most often adjacent 465 to or encompassed by other vegetation. Considering that upland and wetland herbs are rated high in terms of grizzly bear habitat (Park and Petrovcic 2001), more accurate herb cover estimation by SPOT imagery could improve our knowledge and understanding of the status and trends in grizzly bear habitat and ecosystem health analysis.

When conducting a comparative study among multi-sensors, it is also important to consider the effect of the sensors' spectral regions on discrimination of land cover classes. The number of bands present in a particular sensor and the spectral regions used are some of the important factors that determine the usefulness of the data for different applications, including land cover classification studies (Belluco et al. 2006). Joshi et al. (2008) found that ASTER data showed the highest classification accuracy because of its higher number of bands in comparison with Landsat ETM+ and IRS1D LISS III (four bands). To identify the effect of different spectral regions in ASTER, SPOT and Landsat sensors, the classification analysis in the present study was based on all of the bands in each image. Consistent with Joshi et al. (2008), 480 ASTER data were found to be more accurate than Landsat data in classifying land cover classes in this study. However, ASTER data are not necessarily better than SPOT 5 image, although SPOT has fewer spectral bands. The crown closure modelling based on NDVI data also indicated that SPOT resulted in the most accurate map. It can be inferred from the present study that the spatial resolution might be more 485 
important than the spectral region in the discrimination of different vegetation classes and modelling of forest attributes as long as two important bands (Red and NIR) are involved. Landsat data, with the lowest spatial resolution, revealed the lowest classification accuracy, with ASTER and SPOT data providing superior outputs. SPOT data, with the highest spatial resolution, provided the highest classification and 490 modelling accuracy in these tests.

It should also be noted that significant efforts are under way to implement the LDCM to ensure continued availability of Landsat imagery. At the same time, the European Space Agency (ESA) is developing five new missions, called Sentinels, specifically for operational needs (http://www.esa.int/esaLP/SEMM4T4KXMF_LPg mes_0.html). Under these missions, the Sentinel-2 polar-orbiting satellites, with the first planned launch in 2012, will provide systematic global acquisitions of highresolution multi-spectral imagery with a high revisit frequency. Specifically, Sentinel-2 will provide enhanced continuity of the multi-spectral imagery provided by the French SPOT series of satellites (for resolutions of typically $\geq 10 \mathrm{~m}$ ).

\section{Acknowledgements}

This study was supported by the Natural Sciences and Engineering Research Council of Canada, the Alberta Innovation and Science Fund, and the many partners of the Foothills Model Forest Grizzly Bear Research Program. We acknowledge the valuable comments and suggestions from three anonymous reviewers, whose comments 505 helped to improve the manuscript.

\section{References}

Antrop, M. and Van Eetvelde, V., 2000, Holistic aspects of suburban landscapes: visual image interpretation and landscape metrics. Landscape and Urban Planning, 50, pp. 43-58.

Arvidson, T., Goward, S.N., Gasch, J. and Williams, D.L., 2006, Landsat 7 long-term 510 acquisition plan: development and validation. Photogrammetric Engineering and Remote Sensing, 70, pp. 1137-1146.

Benrens, C.E., 2010, Landsat and the Data Continuity Mission. Congressional Research Service Reports on Miscellaneous Topics. Available online at: http://www.fas.org/sgp/crs/misc/ R40594.pdf (accessed July 2010).

ini, P., Andefouet, S., Rion, C. and Payri, C., 2003, A comparison of Landsat ETM+, SPOT HRV, Ikonos, ASTER, and airborne MASTER data for coral reef habitat mapping in South Pacific islands. Canadian Journal of Remote Sensing, 29, pp. 187-200.

Clinton, N., Holt, A., YAn, L. and Gong, P., 2008, An accuracy assessment measure for object based image segmentation. International Archives of the Photogrammetry, Remote 520 Sensing and Spatial Information Sciences, 37, pp. 1189-1194.

Cohen, W.B., Spies, T.A. and Fiorella, M., 1995, Estimating the age and structure of forests in a multi-ownership landscape of western Oregon, U.S.A. International Journal of Remote Sensing, 16, pp. 721-746.

Darwish, A., Leukert, K. and Reinhardt, W., 2003, Image segmentation for the purpose of 525 object-based classification. In IEEE Proceedings of IGARSS'2003, Toulouse, France, pp. 2039-2041.

Desclée, B., Bogaert, P. and Defourney, P., 2006, Forest change detection by statistical object-based method. Remote Sensing of Environment, 102, pp. 1-11.

Foody, G.M., 2002, Status of land cover classification accuracy assessment. Remote Sensing of 530 Environment, 80, pp. 185-201.

GeoAnalytic, 1999, Application of Evidential Reasoning to the Classification of Grizzly Bear Habitat using Landsat TM and Ancillary Data. Milestone Report 1. Canada Centre for Remote Sensing. 
Goward, S.N, Arvidson, T.J., Williams, D.L., Faundeen, J., Irons, J. and Franks, S., 2006, 535 Historical record of Landsat global coverage: mission operations, NSLRSDA, and international cooperator stations. Photogrammetric Engineering and Remote Sensing, 70, pp. 1155-1170.

Husch, B., Beers, T.W. and Kershaw, J.A., Jr., 2003, Forest Mensuration (Hoboken: John Wiley and Sons).

Hutchinson, M.F., 1989, A new method for gridding elevation and stream line data with automatic removal of pits. Journal of Hydrology, 106, pp. 211-232.

Joshi, P.K., Gupta, B. and Roy, P.S., 2008, Spectral evaluation of vegetation features using multi-satellite sensor system (Terra ASTER, Landsat ETM+ and IRS 1D LISS III) in man-made and natural landscape. Sensor Review, 28, pp. 52-61.

Kato, M., Sonobe, T., Oyanagi, M., Yasuoka, Y., Tamura, M. and Hayashi, M., 2001, ASTER data utilisation for wetland mapping and forest mapping. In Proceedings of the 22th Asian Conference on Remote Sensing, 5-9 November 2001, Singapore. Available online at: http://www.crisp.nus.edu.sg/ acrs2001/pdf/253kato.pdf (accessed 10 December 2008).

Kauth, R.J. and Thomas, G.S., 1976, The Tasseled Cap - a graphical description of the spectral-temporal development of agricultural crops as seen by Landsat. In Proceedings of the Symposium on Machine Processing of Remotely Sensed Data, Purdue University, West Lafayette, IN, pp. 4B41-4B51.

Keramitsogloua, I., Kontoes C., Sykioti, O., Sifakis, N. and Xofis, P., 2008, Reliable, 555 accurate and timely forest mapping for wildfire management using ASTER and Hyperion satellite imagery. Forest Ecology and Management, 255, pp. 3556-3562.

Lewinsky, S., 2005, Land use classification of ASTER image - Legionowo test site. In Proceedings of 25th EARSeL Symposium, 6-9 June 2005, Porto, Portugal. Available online at: http://www.definiens.com/pdf/publications/st_lewinski_porto2005.pdf 560 (accessed 10 December 2008).

Linke, J., Franklin, S.E., Huettmann, F. and Stenhouse, G.B., 2005, Seismic cutlines, changing landscape metrics and grizzly bear landscape use in Alberta. Landscape Ecology, 20, pp. 811-826.

Lobell, D.B. and Asner, G.P., 2003, Comparison of Earth Observing-1 ALI and Landsat 565 ETM+ for crop identification and yield prediction in Mexico. IEEE Transactions on Geoscience and Remote Sensing, 41, pp. 1277-1282.

McDermid, G.J., Franklin, S.E. and Ledrew, E.F., 2005, Remote sensing for large-area habitat mapping. Progress in Physical Geography, 29, pp. 449-474.

Meinel, G. and Neubert, M., 2004, A comparison of segmentation programs for high resolu- 570 tion remote sensing data. International Archives of the Photogrammetry, Remote Sensing and Spatial Information Sciences, 35, pp. 1097-1102.

Michener, W.K. and Hounoulis, P.F., 1997, Detection of vegetation changes associated with extensive flooding in a forested ecosystem, Photogrammetric Engineering and Remote Sensing, 63, pp. 1363-1374.

Ministry for the Environment, 2005, The New Zealand Land Cover Database. Available online at: http://www.mfe.govt.nz/issues/land/land-cover-dbase/ (accessed December 2008).

Muchoney, D.M. and HaAck, B.N., 1994, Change detection for monitoring forest defoliation. Photogrammetric Engineering and Remote Sensing, 60, pp. 1243-1251.

Neubert, M. and Meinel, G., 2003, Evaluation of segmentation programs for high resolution remote sensing applications. In Proceedings of the Joint ISPRS/EARSeL Workshop on High Resolution Mapping from Space 2003, M. Schroeder, K. Jacobsen and C. Heipke (Eds), CD-ROM.

Nielsen, S.E., Boyce, M.S. and Stenhouse, G.B., 2004, Grizzly bears and forestry. I. Selection 585 of clearcuts by grizzly bears in west-central Alberta, Canada. Forest Ecology and Management, 199, pp. 51-65. 
PAPE, A.D. and Franklin, S.E., 2008, MODIS-based change detection for grizzly bear habitat mapping in Alberta. Photogrammetric Engineering and Remote Sensing, 74, pp. 973-986.

Park, B. and Petrovcic, S., 2001, Classification of avalanche chutes in the Albert river drainage. Available online at: http://www.env.gov.bc.ca/kootenay/wld/reports/pdf/SFP Avalanche_Albert_River/Albert\%20av\%20chute\%20report.pdf (accessed April 2009).

Pu, R. and Gong, P., 2004, Wavelet transform applied to EO-1 Hyperion data for forest LAI and crown closure mapping. Remote Sensing of Environment, 91, pp. 212-224.

Richter, R., 1990, A fast atmospheric correction applied to Landsat TM images. International Journal of Remote Sensing, 10, pp. 1429-1435.

Song, C., Woodcock, C.E., Seto, K.C., Lenney, M.P. and Macomber, S.A., 2001, Classification and change detection using Landsat TM data: when and how to correct atmospheric effects? Remote Sensing of Environment, 75, pp. 230-244.

Spot Image, 2008, SPOT International Price List. Available online at: http://www.spotimage.fr/ automne_modules_files/standard/public/p336_ba582c667a21f3b7d1108ad9773629fd SPOTPriceList_2008-1410.pdf (accessed 7 April 2009).

Stenhouse, G. and Graham, K., 2005, Foothills Model Forest Grizzly Bear Research Program 1999-2003 Final Report (Hinton, Alberta: Foothills Model Forest).

Toutin, T., 1995, Multi-source data fusion with an integrated and unified geometric modelling. EARSel Advances in Remote Sensing, 4, pp. 118-129.

Tucker, C.J., Grant, D.M. and Dykstra, J.D., 2004, NASA's global orthorectified Landsat data set. Photogrammetric Engineering and Remote Sensing, 70, pp. 313-322.

Wulder, M.A., DechKa, J.A., Gillis, M.A., Luther, J.E., Hall, R.J., Beaudoin, A. and 610 Franklin, S.E., 2003, Operational mapping of the land cover of the forested area of Canada with Landsat data: EOSD land cover program. The Forestry Chronicle, 79, pp. 1075-1083.

Wulder, M.A., White, J.C., Goward, S.N., Maskek, J.G., Irons, J.R., Herold, M., Cohen, W.B., Loveland, T.R. and Woodcock C.E., 2008, Landsat continuity: issues and 615 opportunities related to Landsat continuity. Remote Sensing of Environment, 112, pp. 955-969. 